Corrigendum

\title{
Corrigendum to "Circulating Levels of Sirtuin 4, a Potential Marker of Oxidative Metabolism, Related to Coronary Artery Disease in Obese Patients Suffering from NAFLD, with Normal or Slightly Increased Liver Enzymes"
}

\author{
Giovanni Tarantino (D), ${ }^{1,2}$ Carmine Finelli $\left(\mathbb{D},{ }^{3}\right.$ Franco Scopacasa, ${ }^{4}$ Fabrizio Pasanisi, ${ }^{1}$ \\ Franco Contaldo, ${ }^{1}$ Domenico Capone, ${ }^{5}$ and Silvia Savastano ${ }^{1}$ \\ ${ }^{1}$ Department of Clinical Medicine and Surgery, Federico II University Medical School of Naples, Via Sergio Pansini 5, \\ 80131 Naples, Italy \\ ${ }^{2}$ Centro Ricerche Oncologiche di Mercogliano, Istituto Nazionale Per Lo Studio E La Cura Dei Tumori "Fondazione \\ Giovanni Pascale", IRCCS, 83013 Mercogliano, Italy \\ ${ }^{3}$ Independent Researcher, Naples, Italy \\ ${ }^{4}$ Department of Biochemistry and Medical Biotechnology, Federico II University Medical School of Naples, Via Sergio Pansini 5, \\ 80131 Naples, Italy \\ ${ }^{5}$ Department of Neuroscience, Unit of Clinical Pharmacology, Federico II University Medical School of Naples, Via Sergio Pansini 5 , \\ 80131 Naples, Italy
}

Correspondence should be addressed to Giovanni Tarantino; tarantin@unina.it

Received 19 May 2018; Accepted 11 July 2018; Published 13 August 2018

Copyright ( 2018 Giovanni Tarantino et al. This is an open access article distributed under the Creative Commons Attribution License, which permits unrestricted use, distribution, and reproduction in any medium, provided the original work is properly cited.

In the article titled "Circulating Levels of Sirtuin 4, a Potential Marker of Oxidative Metabolism, Related to Coronary Artery Disease in Obese Patients Suffering from NAFLD, with Normal or Slightly Increased Liver Enzymes" [1], the second author, Carmine Finelli, is not affiliated to the Stella Maris Mediterraneum Foundation and should be listed as an independent researcher. The corrected list of affiliations is shown above.

\section{References}

[1] G. Tarantino, C. Finelli, F. Scopacasa et al., "Circulating levels of Sirtuin 4, a potential marker of oxidative metabolism, related to coronary artery disease in obese patients suffering from NAFLD, with normal or slightly increased liver enzymes," Oxidative Medicine and Cellular Longevity, vol. 2014, Article ID 920676, 10 pages, 2014. 


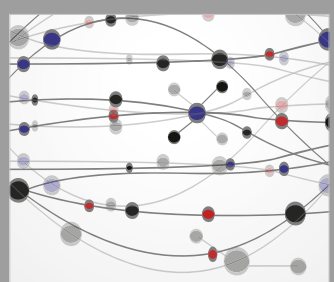

The Scientific World Journal
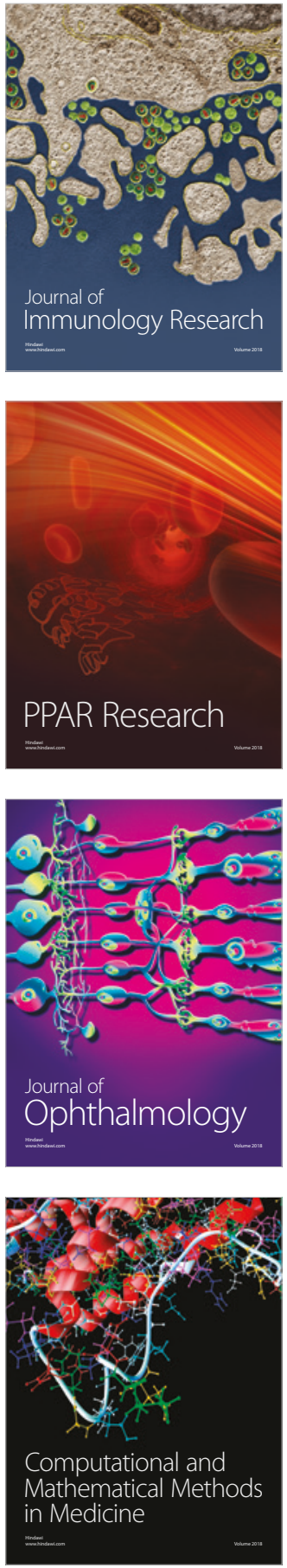

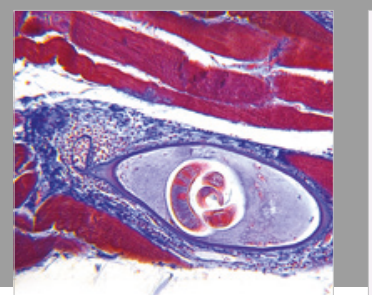

Gastroenterology Research and Practice

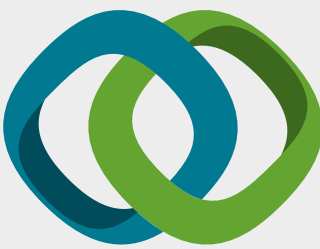

\section{Hindawi}

Submit your manuscripts at

www.hindawi.com
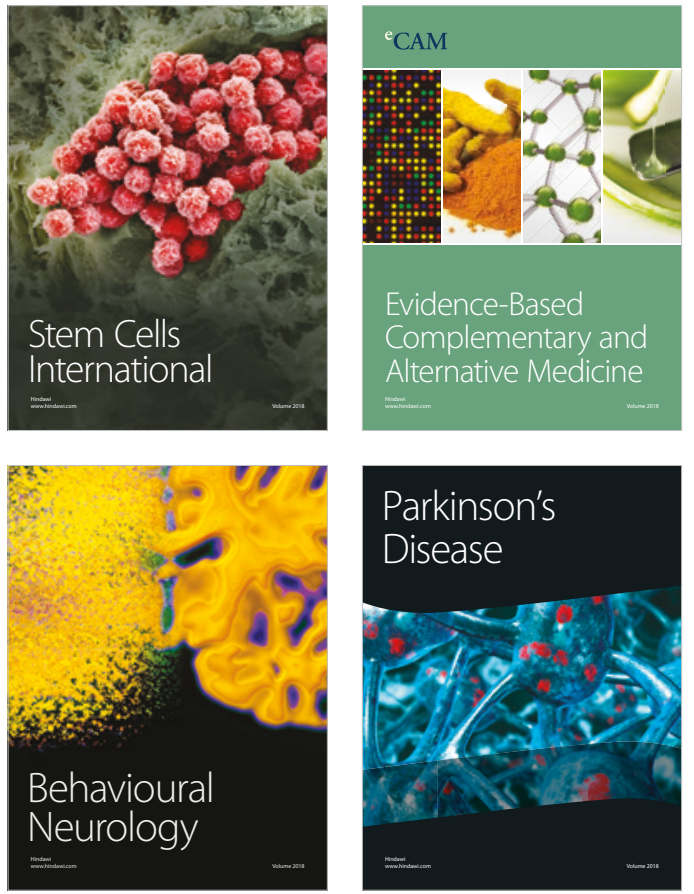

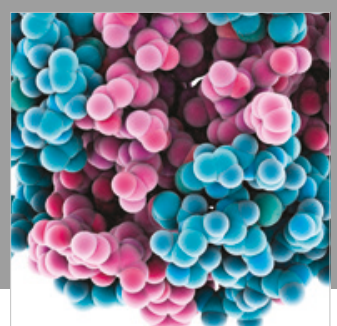

ournal of

Diabetes Research

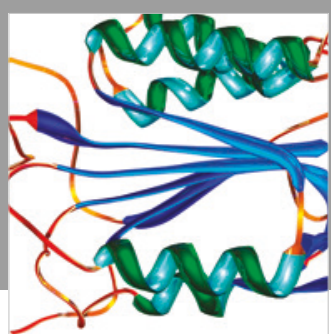

Disease Markers
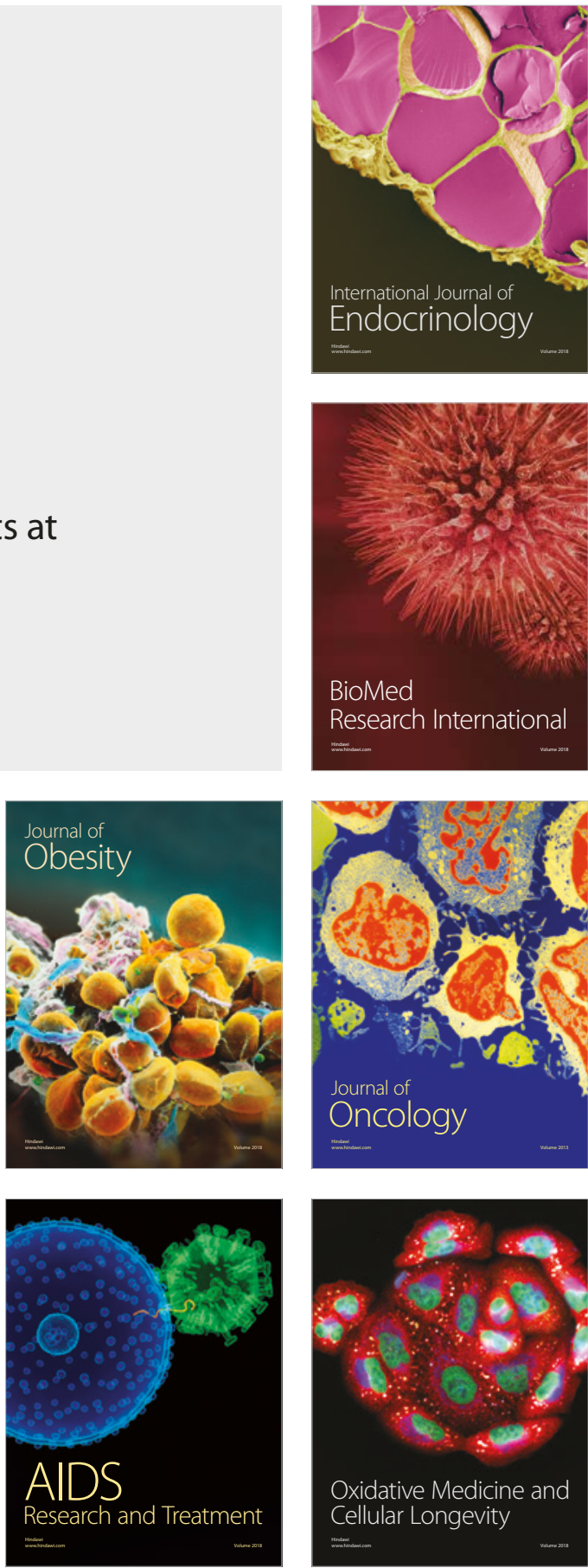